\title{
Vigorous physical activity and obesity in children: the role of physical fitness
}

\begin{abstract}
We proposed a physical fitness oriented approach in the prevention of childhood obesity based on the literature and our own studies. We believe that obesity prevention should focus on various attributes of physical fitness using moderate and vigorous intensity physical activities. We specifically argued for the importance of vigorous physical activity in reaching energy balance and preventing obesity in children.
\end{abstract}

Keywords: moderate and vigorous physical activity, childhood obesity, physical fitness, cardiorespiratory fitness, physical training, child development
Volume 7 Issue I - 2017

\author{
Zenong Yin,' Zhixiong Zhou, ${ }^{2}$ Wenxi (Kevin) \\ Liu,' Hong Ren ${ }^{3}$ \\ 'Department of Kinesiology, Health and Nutrition, The \\ University of Texas at San Antonio, USA \\ ${ }^{2}$ School of Physical Education and Coaching Science, The Capital \\ University of Physical Education and Sports, China \\ ${ }^{3}$ School of Sport Sciences, The Beijing Sport University, China
}

\begin{abstract}
Correspondence: Zenong Yin, Department of Kinesiology, Health and Nutrition, The University of Texas at San Antonio, I UTSA Circle, San Antonio, TX 78249, USA, Tel: 21 0-458-5650; Fax: 210-458-5873; Email zenong.yin@utsa.edu
\end{abstract}

Received: June 22, 2017 | Published: July 17, 2017
Abbreviations: PA, physical activity; MVPA, moderate and vigorous physical activity; VPA, vigorous physical activity; CRF, cardiorespiratory fitness

\section{Introduction}

A plethora of epidemiological studies has consistently linked high levels of physical activity (PA) and cardiorespiratory fitness (CRF) with reduced obesity in children. ${ }^{1,2}$ Although CRF is hereditary to a large extent, physical training and exercise can increase CRF which is known to mediate the effects of PA on adiposity and cardiometabolic biomarkers in adults. ${ }^{3,4}$ In fact, it has been shown that improvement in CRF can lower all-cause mortality and cardiometabolic risk without a reduction in body weight or adiposity in adults. Although the pathway of influence of PA on adiposity is known, ${ }^{5,6}$ the mechanism of physical fitness in maintaining energy balance and attenuating adiposity remains unclear at this time. ${ }^{3,7,8}$ Speculatively, increased fatfree mass can raise energy expenditure above and beyond the energy burned during vigorous physical activity (VPA). ${ }^{9}$ Furthermore, it has been observed that energy expenditure remains elevated after highintensity exercise sessions. ${ }^{10,11}$ For example, Yoshioka et al reported that post-exercise resting $\mathrm{O}_{2}$ uptake and fat oxidation were greater after high-intensity PA (70-75\% maximum $\mathrm{O}_{2}$ uptake) than low to moderate intensity PA (35-40\% maximum $\mathrm{O}_{2}$ uptake) suggesting VPA induced a greater increase in resting metabolic rate. ${ }^{12}$ There is evidence that energy intake does not significantly increase to compensate for increased energy expenditure following high-intensity PA. ${ }^{13,14}$ Finally, post-exercise thematic effect of food is increased especially following high-intensity exercise inversely to levels of adiposity in adults. ${ }^{15}$

PA and physical fitness are often presented as mutually inclusive constructs in the literature, disrespect the fact that the former is a behavioral quality, and the latter is a physiological quality. ${ }^{16}$ In most of the cases, CRF was incorrectly construed as physical fitness due to a conceptual misunderstanding on the part of the researchers. Physical fitness is defined as body's ability to achieve optimal levels of physical performance in dealing with physiological stress to the body. Ross Pate defined health-related physical fitness as "a state characterized by (a) an ability to perform daily activities with vigor, and (b) demonstration of traits and capacities that are associated with low risk of premature development of the hypokinetic diseases (i.e., those associated with physical inactivity)". ${ }^{17}$ Attributes of physical fitness include CRF (or endurance), speed, muscle strength, agility, flexibility, and body composition. ${ }^{18}$ Sallis et al., ${ }^{19}$ found that higher level of habitual PA was associated with five components of healthrelated fitness (the mile run, skin-fold tests, pull-ups, sit-ups, and the sit-and-reach test) in fourth-grade children. Because levels of CRF are closely associated with all-cause mortality and risk of chronic diseases such as cardiovascular disease and type 2 diabetes, ${ }^{2}$ obesity intervention programs have primarily targeted CRF with aerobic activities while some also incorporated resistant training activities. However, majority of PA-focused programs have produced small effect due to inadequate intervention dose or poor program quality. ${ }^{20-22}$

We have successfully demonstrated that children's body composition is responsive to physical fitness oriented PA intervention that targets multiple attributes of physical fitness (i.e., more than $\mathrm{CRF}$ ) and applies the physiological principles of physical training. ${ }^{23-25}$ Metabolically significant changes were observed in body fat percent, fat-free mass, and bone density in addition to measures of physical fitness. Participants in our studies were normal weight and overweight children ages 3 to 11years enrolled in childcare centers and elementary schools. Important elements of our intervention programs included: offering daily opportunities for VPA, monitoring of activity intensity (target heart rate $>140$ beats/minutes for VPA), using age-appropriate, fun activities for development of all attributes of physical fitness, providing lesson plans and additional equipment for reducing children's non-active (waiting) time, and training program staff on instruction and group management strategies. We have developed our intervention protocols based on feasibility demonstrated in experimental studies of similar age children. ${ }^{7,26}$ Currently we are conducting a randomized field trial to test the effects of a school-based intervention on body composition and physical fitness in 790 middle school students in three cities in China (ChiCTR-IOR-14005388). The PA intervention will target on CRF, muscle strength, agility, and flexibility during physical education class and an after-school exercise 
program. Parents of the students in the intervention condition will receive training on promoting and supporting healthy lifestyle habits at home. The study will allow us to scrutinize the contributions of activity intensity and dose on all attributes and physical fitness as well as body composition in children.

There are legitimate concerns that VPA is not appropriate for children especially overweight and obese children and can increase the risk of injury. ${ }^{27,28}$ By following the physiological principles of physical training and child development, we and others have shown that children on wide spectrum of age and obesity can complete long-term programs of VPA (age-adjusted relative intensity: 70$80 \%$ of maximum heart rate). ${ }^{24,29,30}$ Risk for injury in intervention studies using VPA is no different from what is reported in children participating in recreational sport play. ${ }^{24,29,30}$ However, it is unrealistic to expect all children starting the program with all activities being vigorous. Carefully designed activities based on the progressive principle of physical training coupled with regular monitoring by trained staff can keep children safe, engaged, and motivated, and prevent drop-out during early stage of the program. ${ }^{31}$ Opting for a laissez-faire approach by not challenging children with sufficient amount of vigorous activities can only lead to a disappointing outcome that discourages future effort in child's pursue of healthy weight. Meanwhile, researchers must understand that children are not miniature adults in applying the training principles that were established for adult population. ${ }^{32}$

Intervention approach with a "requisite induction of negative energy imbalance" has largely been ineffective in preventing childhood obesity. ${ }^{33}$ Controversial to some, we have argued for a physical fitness oriented approach without dietary restriction to improve body composition in children that is characterized by vigorous physical activities targeting multiple attributes of physical fitness. ${ }^{28,34}$ Randomized intervention studies are needed to examine its efficacy and optimal dose in normal as well as overweight and obese children. ${ }^{35,36}$

\section{Acknowledgements}

Special gratitude is extended to Dr. Bernard (Bob) Gutin for his mentoring of the first author over the years. This work was supported in part by the Beijing Social Science Funding Project (No. 16YTB018), Serving National Special Needs in Doctoral Talents Development Program-Performance Training and Health Promotion for Adolescent, and the Scientific Research Project of Beijing Educational Committee (No. KM201710029002), Support Program for High-Level Teacher Team Development of Beijing Municipal Institutions.

\section{Conflict of interest}

The author declares no conflict of interest.

\section{References}

1. Rauner A, Mess F, Woll A. The relationship between physical activity, physical fitness and overweight in adolescents: a systematic review of studies published in or after 2000. BMC Pediatr. 2013;13:19-19.

2. Fogelholm M. Physical activity, fitness and fatness: relations to mortality, morbidity and disease risk factors. A systematic review. Obes Rev. 2010;11(3):202-221.

3. McMurray RG, Bo Andersen L. The Influence of Exercise on Metabolic Syndrome in Youth: A Review. American Journal of Lifestyle Medicine. 2010;4(2):176-186.
4. Sassen B, Cornelissen VA, Kiers H, et al. Physical fitness matters more than physical activity in controlling cardiovascular disease risk factors. Eur J Cardiovasc Prev Rehabil. 2009;16(6):677-683.

5. Chaput JP, Klingenberg L, Rosenkilde M, et al. Physical activity plays an important role in body weight regulation. J Obes. 2011;2011:pii:360257.

6. Thompson D, Karpe F, Lafontan M, et al. Physical activity and exercise in the regulation of human adipose tissue physiology. Physiol Rev. 2012;92(1):157-191.

7. Gutin B, Barbeau P, Yin Z. Exercise interventions for prevention of obesity and related disorders in youths. Quest. 2004;56(1):120-141.

8. Rauner A, Mess F, Woll A. The relationship between physical activity, physical fitness and overweight in adolescents: a systematic review of studies published in or after 2000. BMC Pediatrics. 2013;13(1):19.

9. Dulloo AG, Jacquet J. Adaptive reduction in basal metabolic rate in response to food deprivation in humans:a role for feedback signals from fat stores. Am J Clin Nutr. 1998;68(3):599-606.

10. Brockman L, Berg K, Latin R. Oxygen uptake during recovery from intense intermittent running and prolonged walking. J Sports Med Phys Fitness. 1993;33(4):330-336.

11. Brehm BA, Gutin B. Recovery energy expenditure for steady state exercise in runners and nonexercisers. Med Sci Sports Exerc. 1986;18(2):205-210.

12. Yoshioka M, Doucet E, St Pierre S. Impact of high-intensity exercise on energy expenditure, lipid oxidation and body fatness. Int J Obes Relat Metab Disord. 2001;25(3):332-339.

13. Imbeault P, Saint Pierre S, Alméras N, et al. Acute effects of exercise on energy intake and feeding behaviour. Br J Nutr. 1997;77(4):511-521.

14. Stubbs RJ, Sepp A, Hughes DA, et al. The effect of graded levels of exercise on energy intake and balance in free-living men, consuming their normal diet. Eur J Clin Nutr. 2002;56(2):129-140.

15. Segal KR, Pi Sunyer FX. Exercise and obesity. The Medical clinics of North America. 1989;73(1):217-236.

16. Caspersen CJ, Powell KE, Christenson G. Physical activity, exercise, and physical fitness: definitions and distinctions for health-related research. Public Health Rep. 1985;100(2):126-131.

17. Pate RR. The Evolving Definition of Physical Fitness. Quest. 1988;40(3):174-179.

18. Malina RM. Physical activity and fitness: Pathways from childhood to adulthood. Am J Hum Biol. 2001;13(2):162-172.

19. Sallis JF, McKenzie TL, Alcaraz JE. Habitual physical activity and health-related physical fitness in fourth-grade children. Am J Dis Child. 1993;147(8):890-896.

20. Sun C, Pezic A, Tikellis G, et al. Effects of school-based interventions for direct delivery of physical activity on fitness and cardiometabolic markers in children and adolescents: a systematic review of randomized controlled trials. Obes Rev. 2013;14(10):818-838.

21. Dobbins M, Husson H, DeCorby K, et al. School-based physical activity programs for promoting physical activity and fitness in children and adolescents aged 6 to 18. Cochrane Database Syst Rev. 2013;2:CD007651.

22. Wang $\mathrm{Y}$, Cai $\mathrm{L}, \mathrm{Wu} \mathrm{Y}$, et al. What childhood obesity prevention programmes work? A systematic review and meta-analysis. Obes rev. 2015;16(7):547-565.

23. Zhou Z, Ren H, Yin Z, et al. A policy-driven multifaceted approach for early childhood physical fitness promotion: impacts on body composition and physical fitness in young Chinese children. BMC pediatrics. 2014;14:118. 
24. Yin Z, Moore JB, Johnson MH, et al. The impact of a 3-year after-school obesity prevention program in elementary school children. Child Obes. 2012;8(1):60-70.

25. Gutin B, Yin Z, Johnson M, et al. Preliminary findings of the effect of a 3-year after-school physical activity intervention on fitness and body fat:the Medical College of Georgia Fit kid Project. Int J Pediatr Obes. 2008;3(Suppl 1):3-9.

26. Yin Z, Parra-Medina D, Cordova A. Míranos! Look at us, we are healthy! An environmental approach to early childhood obesity prevention. Childhood obesity (Print). 2012;8(5):429-439.

27. Nauta J, Martin Diener E, Martin BW, et al. Injury risk during different physical activity behaviours in children:a systematic review with bias assessment. Sports med. 2015;45(3):327-336.

28. Nettle H, Sprogis E. Pediatric exercise: truth and/or consequences. Sports Med Arthrosc. 2011;19(1):75-80.

29. Barbeau P, Johnson MH, Howe CA, et al. Ten months of exercise improves general and visceral adiposity, bone, and fitness in black girls. Obesity (Silver Spring). 2007;15(8):2077-2085.
30. Davis CL, Pollock NK, Waller JL, et al. Exercise dose and diabetes risk in overweight and obese children: a randomized controlled trial. JAMA. 2012;308(11):1103-1112.

31. Tolfrey. Responses to training. In: NA, NSM, editors. Paediatric Exercise Physiology. UK: Churchill Livingstone; 2007. p. 213-234.

32. Rowland T, Saltin B. Learning from children: the emergence of pediatric exercise science. Journal of Applied Physiology. 2008;105(1):322-324.

33. Hanks LJ, Simpson T, McCormick K, et al. Pediatric obesity prevention: From naive examination of energy imbalance towards strategies that influence the competition for nutrient resources among tissues. World $J$ Clin Pediatr. 2015;4(4):50-54.

34. Strong WB, Malina RM, Blimkie CJ, et al. Evidence based physical activity for school-age youth. J Pediatr. 2005;146(6):732-737.

35. Watts K, Jones TW, Davis EA, et al. Exercise training in obese children and adolescents: current concepts. Sports med. 2005;35(5):375-392.

36. Gutin B. How can we help people to develop lean and healthy bodies? A new perspective. Research quarterly for exercise and sport. 2013;84(1):1-5. 